\title{
Sentido pessoal, significado social e atividade de estudo: uma revisão teórica
}

\author{
Flávia da Silva Ferreira Asbahr \\ Universidade Estadual Paulista - SP
}

\section{Resumo}

Diante do aumento da literatura que utiliza os conceitos de sentido e significado e da grande dispersão semântica destes termos, nosso objetivo é apresentar tais conceitos na Psicologia Histórico-Cultural a partir de fontes primárias desta teoria, focando obras de Vigotski e Leontiev. O conceito de sentido aparece em Vigotski no seu texto "Pensamento e Palavra", em que analisa a relação entre pensamento e linguagem. Leontiev apropria-se deste conceito denominando-o de "sentido pessoal" e relacionando-o com a atividade e a consciência. Nosso segundo objetivo é, assim, analisar teoricamente a formação da consciência e sua relação com os processos educacionais tendo como foco a atividade de estudo. Como síntese, destaca-se que a ocorrência da aprendizagem depende do sentido que esta tenha para o sujeito, o que requer que o professor estruture a atividade de estudo de modo que os conteúdos a serem aprendidos tenham lugar estrutural na atividade dos estudantes.

Palavras-chave: Educação, Psicologia Histórico-Cultural, consciência.

\section{Personal sense, social meaning and study activity: a theoretical review}

\begin{abstract}
Taking into account the increasing number of psychological and pedagogical scholarship which uses the concepts of meaning and sense and the wide dispersion of these terms, our goal is to introduce such concepts in Historic-Cultural Psychology, from Vygotsky's and Leontiev's works. The concept of meaning appears in the work of Vygotsky, in "Thought and Word," which examines the relationship between thought and language. Leontiev appropriates this concept and calls it as "personal sense". He relates it with consciousness and human activity. Our second goal is, therefore, to analyze theoretically the formation of consciousness and its relationship to educational processes, focusing on the study activity. As a result, we claim that for the school learning to happen, the study actions of the students must have a personal sense, which requires the teacher to structure the study activity so that objects to be learned have structural place in the activity of the students.
\end{abstract}

Keywords: Education, Historic-Cultural Psychology, conscience.

\section{Sentido personal, significado social y actividad de estudio: una revisión teórica}

\section{Resumen}

Considerando el aumento de la literatura psicológica y pedagógica que utiliza los conceptos de sentido y significado y la gran dispersión semántica de estos términos nuestro primer objetivo es presentar tales conceptos en la Psicología Histórico-Cultural con base en las obras de Vigotski y Leontiev. En la obra de Vigotski el concepto de sentido aparece en el texto "Pensamiento y Palabra", en el que el autor analiza la relación entre pensamiento y lenguaje. Leontiev se apropia de este concepto denominándolo de "sentido personal" y lo relaciona con la actividad y la conciencia humana. Nuestro segundo objetivo es analizar teóricamente la formación de la conciencia y su relación con los procesos educacionales, centrándonos en la actividad de estudio, actividad principal del niño en edad escolar, y en la dinámica, el significado social y el sentido personal en esta actividad.

Palabras Clave: educación; Psicología Histórico-Cultural; conciencia. 


\section{Introdução}

Tanto na literatura pedagógica como na psicológica assistimos a um aumento de produções e pesquisas que utilizam os conceitos de sentido e de significado (Aguiar, 2006; González Rey, 2007). Em qualquer visita a congressos dessas áreas, chama a atenção a quantidade de trabalhos nos quais esses conceitos aparecem logo no título. González Rey (2007) também aponta sua ampla profusão na literatura psicológica e alerta para os perigos de banalização de uma categoria quando "está em moda" e passa a ser usada acriticamente, deslocada de seu campo teórico.

Isto fica evidente no caso do sentido e do significado, pois estes são conceitos que apresentam grande dispersão semântica, sendo usados em várias áreas do conhecimento (Psicologia, Linguística, Literatura, etc.) e a partir de diferentes concepções teóricas.

Além disso, segundo Barros, Paula, Pascual, Colaço \& Ximenes (2009), no próprio conjunto da obra de Vigotski o conceito de sentido tem pouca notoriedade, sendo trabalhado mais especificamente no capítulo "Pensamento e palavra" (2000a). Mesmo assim, pode ser considerado um "divisor de águas" em sua obra, pois permite avançar na compreensão da constituição da consciência humana e superar a dicotomia razão e emoção na investigação da relação pensamento e linguagem.

Como resultado tanto do modismo que banaliza tais conceitos como de sua pouca presença e aprofundamento na própria obra vigotskiana, avaliamos que os conceitos de sentido e de significado têm adquirido uma compreensão bastante subjetivista, como se o sentido fosse atribuído pelo sujeito independentemente de sua atividade social. Além disso, em muitos casos falta consistência teórica acerca de tais conceitos, ou seja, não se explicita qual é o conceito que se está utilizando e a partir de qual referencial teórico.

Os conceitos de sentido e de significado não são uma exclusividade da obra dos autores da Psicologia Histórico-Cultural. Segundo Namura (2004), que apresenta um panorama do conceito de sentido de modo a situá-lo na história da Psicologia, tal conceito é tema da área desde sua pré-história como ciência e tem sua origem na polêmica entre razão e emoção, presente no corpo teórico-metodológico da Psicologia até os dias de hoje. A explicação sobre o sentido, seja em uma vertente racionalista, seja em uma vertente empirista, foca-se numa compreensão dualista de homem, que cinde sujeito-objeto, razão-emoção, subjetivo-objetivo.

Vigotski busca superar tais dualismos e formula o conceito de "sentido" para ressaltar aquilo que é especificamente humano no homem, ou seja, sua "capacidade de criação e autoprodução nos seus modos e condições de existência" (Namura, 2004, p.91). Com o conceito de sentido, o autor avança em sua investigação acerca da constituição da consciência humana e estabelece a unidade entre cognição e emoção. Na mesma perspectiva, Leontiev (1978) alerta-nos que a Psicologia burguesa estudou o sentido como fenômeno da consciência e da linguagem, tomando-o como fenômeno em si, desvinculado da vida do sujeito. O autor critica tais concepções e propõe que o sentido é "antes de mais nada uma relação que se cria na vida, na actividade do sujeito" (p.97).

Diante do que foi dito, o objetivo deste texto é apresentar quais são os conceitos de sentido e significado na Psicologia Histórico-Cultural, tendo como referência os escritos de Vigotski e Leontiev. Embora na atualidade outros autores se dediquem ao estudo dos conceitos anunciados, entendemos ser de fundamental importância resgatar e compreender as fontes primárias da teoria em foco, de forma a aprofundar a compreensão teórica acerca da origem destes conceitos. O conceito de sentido aparece primeiramente na obra de Vigotski, quando o filósofo soviético estuda a relação entre o pensamento e a linguagem; depois Leontiev apropria-se deste conceito, nomeia-o como "sentido pessoal" e relaciona-o diretamente com a atividade e a consciência humana.

No presente estudo discutiremos também a relação entre o sentido e a atividade de estudo, enfatizando o papel da educação escolar na formação da consciência humana.

\section{A relação entre sentido e significado na constituição da consciência humana: leituras de Vigostki e Leontiev}

Um dos grandes temas de Vigotski (2000a) é a relação entre pensamento e linguagem como chave para a compreensão da consciência humana. Partindo do método de análise por unidades, o autor questiona qual seria a unidade fundamental da relação entre pensamento e linguagem. Conclui que essa unidade está no significado da palavra, pois é a unidade indecomponível de ambos os processos é ao mesmo tempo um fenômeno da linguagem e do pensamento. O significado da palavra é a palavra vista do seu interior.

Assim, o significado da palavra é, ao mesmo tempo, um fenômeno de discurso e intelectual, embora isto não signifique a sua filiação puramente externa a dois diferentes campos da vida psíquica. O significado da palavra só é um fenômeno de pensamento na medida em que o pensamento esteja relacionado à palavra e nela materializado, e viceversa, ou seja, é um fenômeno de discurso apenas na medida em que o discurso esteja vinculado ao pensamento e focalizado por sua luz. É um fenômeno do pensamento discursivo ou da palavra consciente, é a unidade da palavra com o pensamento (2000a, p. 398, grifos do autor).

Nessa perspectiva, o momento central do significado é a generalização. Segundo Vigotski, qualquer palavra é uma generalização, ou seja, um modo original de representar a realidade na consciência. Dessa forma, em uma palavra estão sintetizadas determinadas ações do homem, pois a palavra carrega a máxima generalização dessa(s) ação(ões). Sobre essa discussão, vale ressaltar a relação que Vigotski estabelece entre ação e generalização, ou en- 
tre atividade e linguagem, já que, em muitas interpretações do autor, o significado aparece dissociado da ação, em uma compreensão idealista de sua obra. Para o autor, linguagem e ação são indissociáveis e estão unidas geneticamente desde o início do desenvolvimento da criança.

Por isso mesmo, o significado não é imutável; ao contrário, para Vigotski,os significados desenvolvem-se e se modificam no decorrer do desenvolvimento da criança. Segundo o autor, a relação entre pensamento e palavra deve ser compreendida como um processo, um movimento do pensamento à palavra e da palavra ao pensamento, e nesse processo o pensamento forma-se na palavra: "O pensamento não se exprime na palavra, mas nela se realiza” (p.409).

Ao investigar a relação entre pensamento e linguagem, Vigotski busca distinguir e analisar, em sua dinâmica e estrutura, as linguagens externa, egocêntrica e interior. Nessa discussão apresenta o conceito de sentido, compreendido como central para a compreensão da "dinâmica dos significados" da linguagem verbal (Góes \& Cruz, 2006).

Vigotski diferencia o sentido do significado. O sentido, que no caso da linguagem interior tem predomínio sobre o significado, é mais amplo que o significado: é a soma de todos os fatos psicológicos que a palavra desperta em nossa consciência. Além disso, o autor ressalta o caráter instável do sentido e apresenta sua relação com o significado:

[...] o sentido é sempre uma formação dinâmica, fluida, complexa, que tem várias zonas de estabilidade variada. $\mathrm{O}$ significado é apenas uma dessas zonas do sentido que a palavra adquire no contexto de algum discurso e, ademais, uma zona mais estável, uniforme e exata. Como se sabe, em contextos diferentes, a palavra muda facilmente de sentido. O significado, ao contrário, é um ponto imóvel e imutável que permanece estável em todas as mudanças de sentido da palavra em diferentes contextos (2000a, p.465).

O sentido enriquece a palavra a partir de seu contexto e esta é a lei fundamental da dinâmica do significado das palavras. No caso da linguagem interior, o predomínio do sentido sobre o significado é representado em forma absoluta: a palavra "é uma espécie de coágulo concentrado de sentido" (Vigotski, 2000a, p.470). Há uma primazia do sentido da palavra, pois é uma linguagem para si mesmo, com uma estrutura semântica própria.

Ao introduzir o sentido na investigação sobre a relação pensamento e linguagem, Vigotski (2000a) conclui que o pensamento não coincide absolutamente com a linguagem e que o caminho entre o pensamento e a palavra é indireto e internamente mediado, "por isso o pensamento nunca é igual ao significado direto das palavras" (p. 479). Nessa perspectiva, o autor ressalta uma questão central na construção de sua "psicologia concreta do homem" (2000b): o papel dos motivos e dos afetos na formação do pensamento humano. Afirma o autor:

Por trás do pensamento existe uma tendência afetivo e volitiva. Só ela pode dar resposta ao último porquêna análise do pensamento. Se antes comparamos o pensamento a uma nuvem pairada que derrama uma chuva de palavras, a continuar essa comparação figurada teríamos de assemelhar a motivação do pensamento ao vento que movimenta as nuvens. A compreensão efetiva e plena do pensamento alheio só se torna possível quando descobrimos a sua eficaz causa profunda afetivo-volitiva (p. 479-480, grifos do autor).

Vigotski (2000a) conclui o capítulo "Pensamento e palavra" anunciando o problema da consciência humana, que, segundo o autor, é mais vasto e profundo que o pensamento. Pensamento e linguagem são compreendidos como a chave para a compreensão da consciência, pois o desenvolvimento da palavra e o da consciência estão intrinsecamente vinculados: "A palavra consciente é o microcosmo da consciência humana" (p.486).

Vigotski avança ao introduzir o conceito de sentido na investigação sobre a relação entre pensamento e linguagem e ao relacioná-lo com a consciência humana, mas ainda assim é um conceito inconcluso em sua obra. Leontiev aprofunda a análise desse conceito e o compreende a partir da atividade humana ${ }^{1}$.

Leontiev $(1978,1983)$ postula que a atividade humana e a consciência constituem uma unidade dialética, ou seja, a consciência é produto subjetivo da atividade dos homens com os objetos e com os outros homens e, ao mesmo tempo, regula a atividade produtora da vida humana. Ao analisar a relação entre a consciência e a atividade, Leontiev rejeita e critica as concepções metafísicas que isolam a consciência da vida real. Propõe, ao contrário, uma análise da consciência a partir das condições sociais e históricas de sua constituição e postula que a consciência é a forma concreta do psiquismo humano.

Segundo Leontiev (1978), os elementos constitutivos da consciência humana são o conteúdo sensível, a significação social ${ }^{2}$ e o sentido pessoal. O conteúdo sensível (sensações, imagens de percepção, representações) é o que produz a base e as condições da consciência, o que cria sua riqueza e seu colorido. É o conteúdo imediato da consciência, mas não exprime toda sua especificidade. Torna-se necessário compreender os outros dois elementos: a significação e o sentido.

As significações sociais devem ser compreendidas como as sínteses das práticas sociais conjuntas, a forma ideal de existência no mundo objetal. Assim, a consciência é reflexo da realidade, "refractada através do prisma das

1 Em nossa análise teórica das obras de Vigotski e Leontiev avaliamos que há continuidade entre suas proposições. Embora existam diferenças entre os autores, o que nos faz afirmar a existência de uma continuidade entre eles é o fato de que ambos partem da mesma concepção de homem e de ciência e especificamente, de Psicologia, orientando suas pesquisas fundamentados no Materialismo Histórico-Dialético como referência ontológica e epistemológica.

2 Ou significado social, dependendo da tradução. Neste trabalho, as duas formas, significado e significação, aparecerão para expressar o mesmo conceito. 
significações e dos conceitos linguísticos, elaborados socialmente" (1978, p.88, grifos do autor).

O conteúdo da consciência social é o sistema de significações, que é fixado na forma de linguagem. Leontiev (1978) define da seguinte forma o conceito de significação social:

A significação é a generalização da realidade que é cristalizada e fixada num vector sensível, ordinariamente a palavra ou a locução. É a forma ideal, espiritual da cristalização da experiência e das práticas sociais da humanidade. [...] A significação pertence, portanto, antes de mais, ao mundo dos fenômenos objectivamente históricos (p.94).

Leontiev também chama a atenção para o duplo sentido do termo significação: em alguns casos, como significação de uma palavra, ou seja, como significação verbal, e em outros,como referência aos conhecimentos, ao conteúdo da consciência social assimilado pelo indivíduo.

Este conceito de significado também está presente na obra de Vigotski, que entende o significado da palavra como unidade de análise da relação entre pensamento e linguagem. Para o autor, os significados são produtos históricos e transitórios e as relações sociais neles se refletem; são produtos das condições objetivas que lhes deram origem e refletem a realidade objetivamente existente de um modo especial, por meio de uma generalização.

Segundo Leontiev, as significações medeiam as relações do homem com o mundo, ou seja, são o reflexo da realidade elaborada historicamente pela humanidade sob a forma de conceitos, saberes ou modos de ação, independentemente da relação individual que os homens estabeleçam com ela. O sistema de significações, embora em eterna transformação, está "pronto" quando o indivíduo nasce, cabendo a este se apropriar dele.

Dessa forma, a significação também se constitui como fenômeno da consciência individual, o que não significa que perca seu conteúdo objetivo, que é o conteúdo social. A forma como o indivíduose apropria de determinadas significações, ou mesmo se se apropria ou não, depende do sentido pessoal que tenha para o sujeito.

Duarte (2004) explica esse processo:

O que dá sentido à atividade desse indivíduo, ou seja, o que conecta sua ação com o motivo dessa ação? A resposta é: são as relações sociais existentes entre ele e o restante do grupo ou, em outras palavras, é o conjunto da atividade social. Somente como parte desse conjunto é que a ação individual adquire um sentido racional (p.53-54).

Segundo Leontiev, o sentido é criado pela relação objetiva entre aquilo que provoca a ação no sujeito (motivo da atividade) e aquilo para o qual sua ação se orienta como resultado imediato (fim da ação). O sentido pessoal traduz a relação do motivo com o fim. Assim, para encontrar o sentido pessoal, é necessário descobrir seu motivo correspondente.
Exemplificamos tal relação com uma situação descrita por Leontiev:

Imaginemos um aluno lendo uma obra científica que the foi recomendada. Eis um processo consciente que visa um objectivo preciso. O seu fim consciente é assimilar o conteúdo da obra. Mas qual é o sentido particular que toma para o aluno este fim e por consequência a acção que Ihe corresponde? Isso depende do motivo que estimula a actividade realizada na acção da leitura. Se o motivo consiste em preparar o leitor para sua futura profissão, a leitura terá um sentido. Se, em contrapartida, se trata para o leitor de passar nos exames, que não passam de uma simples formalidade, o sentido de sua leitura será outro, ele lerá a obra com outros olhos; assimilá-la-á de maneira diferente (1978, p.97).

Partindo desse exemplo, Leontiev $(1978,1983)$ faz uma distinção entre motivos geradores de sentido, ou motivos realmente eficazes, e motivos-estímulos, ou motivos apenas compreensíveis. Os primeiros motivos conferem um sentido pessoal à atividade. Na atividade gerada por um motivo desse tipo há uma relação consciente entre os motivos da atividade e os fins das ações. Os motivos-estímulos, diferentemente, têm função sinalizadora e não geram sentido, e assumem o papel de fatores impulsionadores - positivos ou negativos - da atividade, podendo-se dizer que são motivos externos à atividade do sujeito.

Não há sentidos puros, todo sentido é sentido de algo, é sentido de uma significação. Embora estejam ligados um ao outro e pareçam fundidos na consciência, significados e sentidos têm uma base e uma origem distintas e são regidos por leis diferentes (Leontiev, 1983). Os significados são mais estáveis, já os sentidos modificam-se de acordo com a vida do sujeito e traduzem a relação do sujeito com os fenômenos objetivos conscientizados. Além disso, é o sentido que se exprime na significação, e não o contrário; é o sentido que se concretiza nas significações, da mesma maneira que o motivo se concretiza nos objetivos, e não as significações no sentido.

Leontiev (1983) explicita como em alguns casos essa não coincidência entre sentido e significado se expressa claramente. Toma como exemplo o significado da morte. Uma pessoa pode compreender perfeitamente seu significado, conhecer sua natureza biológica, ter estudado aspectos filosóficos e religiosos desse fenômeno e compreender racionalmente sua inevitabilidade, mas no plano pessoal a morte pode não ter um sentido e aparecer como coisa distante, improvável, principalmente se o sujeito for jovem e saudável. Anos depois, para o mesmo sujeito, a morte tem outro sentido, formou-se nele uma nova consciência acerca disso. Possivelmente não terá havido alteração no sistema de significações acerca da morte e o que terá variadoserá seu sentido. Ressalta-se, assim, o papel das condições objetivas na determinação da diferenciação entre sentido e significado na consciência individual. 
Ademais, além dessa diferenciação entre sentido e significado produzida a partir das vivências individuais do sujeito, há outra contraposição, engendrada no modo de produção capitalista, que funda determinada forma de organização da consciência em nossa sociedade, a qual pode ser chamada de consciência alienada.

Para compreender como se constitui essa consciência alienada, Leontiev apresenta o processo de trabalho nas sociedades ditas primitivas e analisa a formação da consciência nesse cenário. Destaca uma característica importante da consciência nas etapas iniciais de desenvolvimento do homem: "o fato de que os objetos se refletem na língua e na consciência conjuntamente com as necessidades humanas concretizadas - objetivadas - neles" (1983, p.119-120, tradução nossa). Ou seja, o sentido dos fenômenos reais coincidia com as significações elaboradas socialmente e fixadas na linguagem.

Essa união rompeu-se e essa ruptura liga-se intimamente às contradições da produção capitalista, que gera a contraposição entre trabalho manual e trabalho intelectual e aliena a atividade humana. Tais condições produzem uma dualidade real dos significados para o sujeito, o que faz as significações se manifestaremcomo existência independente, tanto como objeto da consciência como em suas formas de conscientização.

Essas significações duais são produto da sociedade capitalista e, dessa forma, têm sua história e desenvolvimento na língua e nas demais formas de consciência social, portanto expressam as vivências ideológicas sociais (religiosas, filosóficas, políticas e outras), embora sua ação permaneça oculta na consciência dos indivíduos concretos.

Voltemos à divisão entre trabalho manual e intelectual: o desenvolvimento histórico do homem ensina-nos que toda atividade humana é, a princípio, uma atividade ideal, teórica. O homem cria produtos ideais, teóricos, que são transformados em objetos para satisfazer suas necessidades práticas de alimentação, vestuário, moradia, etc. No caso da sociedade capitalista, há uma separação entre a atividade ideal e a atividade material prática, o que tem como consequência o distanciamento, na consciência dos homens, dessas duas dimensões da atividade humana.

Tendo como fundamentação a análise de Marx acerca do trabalho alienado, Leontiev analisa como a alienação constituinte da sociedade capitalista tem impactos psicológicos sobre os sujeitos individuais. Para o trabalhador, o sentido do trabalho não é produzir os bens para a satisfação das necessidades humanas, mas sim, ganhar um salário que possa garantir sua sobrevivência, mesmo que de forma insuficiente. No entendimento do trabalhador, suas horas de trabalho não têm o sentido de tecer, fiar, minerar, construir, mas o de ganhar um salário que Ihe permita comer, morar e dormir. Marx (1989) assim explica em que consiste essa exteriorização do trabalho:

Primeiro, que o trabalho é exterior ao trabalhador, ou seja, não pertence à sua essência, que portanto ele não se afirma, mas se nega em seu trabalho, que não se sente bem, mas infeliz, que não desenvolve energia mental e livre, mas mortifica a sua physis e arruína sua mente. Daí que o trabalhador só se sinta junto a si fora do trabalho e fora de si no trabalho. Sente-se em casa quando não trabalha e quando trabalha não se sente em casa (p.153, grifos do autor).

Essas relações sociais alienadas penetram na consciência dos sujeitos e produzem uma discordância entre o resultado objetivo da atividade e seu motivo, ou, em outras palavras, o conteúdo objetivo da atividade não concorda com seu conteúdo subjetivo, o que confere à consciência características particulares. A consciência humana, nesse contexto, torna-se desintegrada, fragmentada, alienada. Essas condições históricas são a causa da inadequação psicológica, da "inautenticidade da consciência" (Leontiev, 1978, p.133). Duarte (2004) aponta que essa ruptura entre sentidos e significados não ocorre apenas para o indivíduo, mas para a sociedade:

Acontece que também para a sociedade o trabalho do operário apresenta uma cisão entre o conteúdo e o sentido. Como estamos falando de uma sociedade capitalista, o sentido que a atividade do operário tem é o de parte necessária do processo de reprodução do capital, ou seja, o sentido é dado pelo valor de troca da força de trabalho. Como se sabe, na análise formulada por Marx o valor de troca é indiferente ao valor de uso da mercadoria. No caso dessa mercadoria específica, a força de trabalho, o valor de troca é indiferente ao trabalho concreto, ou seja, ao conteúdo da ação concreta do operário. Assim, não é apenas para o operário que o sentido do seu trabalho se dissocia do conteúdo deste, esse fenômeno ocorre também para a sociedade. $\mathrm{Na}$ verdade, o sentido pessoal que o trabalho tem para o operário é uma consequência do sentido que esse trabalho tem para a sociedade capitalista (p.58).

Segundo Leontiev, isso explica a aspiração humana de superar a inadequação, a fragmentação da consciência, pois é a própria vida que se encontra inadequada. As contradições da consciência podem, nesse sentido, gerar processos de tomada de consciência e gerar entre os trabalhadores uma revolta contra a ideologia burguesa e a organização social que produz tal ideologia. Leontiev, baseado em Marx, propõe que só na sociedade socialista a consciência pode estar plena, integral, pois o sentido do trabalho é outro, já que os motivos também são outros. O motivo não é mais apenas ganhar um salário e o sentido realiza-se psicologicamente nas significações.

Leontiev faz essa análise baseando-se na experiência do socialismo soviético e nas experiências advindas das lutas dos trabalhadores pelo fim da exploração burguesa e da propriedade privada dos meios de produção, mas em nossa sociedade a ruptura entre sentidos e significados nem sempre gera a tomada de consciência - ao contrário, em muitos casos produz o adoecimento tanto físico como psicológico. Como analisam Asbahr (2005) e Silva (2007), 
as contradições na consciência podem produzir grandes sofrimentos psíquicos e, no limite, o adoecimento psicológico. Esclarece um desses autores:

Em alguns casos, qualquer um desses processos de alienação pode levar o indivíduo a um processo de sofrimento e adoecimento em decorrência da atividade ocupacional. O sofrimento psíquico ocupacional é uma descompensação provocada pela organização do trabalho, o adoecimento se refere ao comprometimento físico e/ou mental de natureza patológica, que pode ser caracterizado e diagnosticado clinicamente. Dependendo da forma como o indivíduo enfrenta seu adoecimento, este pode acarretar sofrimento psíquico, principalmente quando o primeiro limita o indivíduo de fazer determinadas atividades e/ou ações (Silva, 2007, p.08).

Aqui perguntamos: quais são as possibilidades e espaços de superação da desintegração da consciência humana? No limite, temos que apontar a necessidade de uma nova organização social que supere a sociedade capitalista. Vigotski, Leontiev e Marx assinalaram essa necessidade, mas, pensando nos objetivos deste texto e no que diz respeito à Educação e à Psicologia, podemos analisar as possibilidades e limites da educação escolar na superação da consciência alienada. Cabe à escola garantir que os sujeitos humanos tenham acesso ao conhecimento historicamente acumulado e aos modos de produção desse conhecimento, ou seja, a escola pode, por meio do conhecimento, criar condições para que o sujeito se compreenda para além de sua existência individual, isto é, se entenda como ser genérico (Martins, 2004).

Dessa perspectiva, um dos grandes desafios da educação escolar contemporânea é fazer com que a aprendizagem dos conteúdos escolares tenha determinado sentido para os estudantes (Duarte, 2004); mas perguntamos: como ocorre o processo de atribuição de sentido pessoal à atividade de estudo? Para responder a esse questionamento faremos uma breve análise teórica acerca da formação da consciência e sua relação com os processos educacionais, tendo como foco a atividade de estudo, a principal atividade da criança em idade escolar, e a dinâmica significado e sentido nesta atividade.

\section{O sentido pessoal e a atividade de estudo}

Leontiev (1983) dedica o anexo da obra Actividad, conciencia, personalidad para tratar da formação da consciência e sua relação com os processos educacionais a partir de duas questões centrais: o que a criança conscientiza entre aquilo que Ihe foi ensinado e como esse conteúdo se torna consciente para a criança.

Primeiramente, o autor critica o tratamento intelectualista da consciência pela psicologia burguesa, que considera a consciência como pensamento. Segundo Leontiev, o conceito de consciência é mais amplo que o conceito de pensamento e a consciência não pode ser compreendida como a soma de processos como percepção, memória, etc., ela só pode ser entendida em uma interpretação integral.

Leontiev ressalta o papel da educação na formação da consciência, entendida não como a formação de hábitos e funções, mas como formação integral da personalidade humana. Também analisa a aprendizagem consciente do material didático pela criança, enfocando aquilo que ela conscientiza e como ocorre esse processo. Ao examinar alguns experimentos ou situações didáticas, chega a uma primeira conclusão: a criança só conscientiza o material (ou de parte dele) para o qual sua atenção foi atraída. Nesse caso, há um equívoco na proposição de diversos exercícios escolares, pois estes são organizados de maneira que não asseguram a conscientização quanto ao conteúdo proposto, ou seja, o que é proposto pelo docente não coincide com o que é conscientizado pelo estudante.

Para que o sujeito possa se conscientizar doobjeto aquele deve ocupar na atividade realizada um lugar estrutural determinado e constituir-se como objeto de sua ação. Nessa perspectiva, ressalta-se o papel do motivo da atividade de estudo para a criança para que se assegure a atenção e a conscientização do objeto de estudo. No caso da atividade de estudo, a conscientização de um conteúdo depende do seu lugar estrutural dentro da atividade do sujeito. Ou seja, só se conscientizam os objetos das ações que fazem parte da estrutura da atividade.

Vigotski (2006), na mesma perspectiva, ao analisar a criação literária em idade escolar, postula que um dos motivos para a dificuldade da aprendizagem da linguagem escrita pelas crianças é que muitas vezes estas não compreendem para que é necessário escrever, ou seja, a escrita é ensinada de forma mecânica e artificial, desvinculada de sua função social. A própria escolha de temas de redação pela escola é alheia à compreensão dos alunos, pouco afetando sua imaginação e seus sentimentos.

Leontiev afirma que são necessários métodos de ensino que superem estas atividades artificiais, e investiga "como" a criança conscientiza os objetos de estudo. Para tal análise, o conceito de sentido pessoal é essencial e o autor retoma a relação do sentido com o motivo da atividade. Destarte, para se investigar o sentido pessoal de uma atividade ou conhecimento para um sujeito é fundamental analisar seu motivo.

A tese do autor é que a ocorrência da aprendizagem e da conscientização de um determinado conhecimento depende do sentido que esse conhecimento tenha para o sujeito, pois os sentidos, diferentemente dos conhecimentos, dos hábitos e das habilidades, não podem ser ensinados, só poder ser educados.

Nessa perspectiva, o psicólogo soviético apresenta alguns resultados de uma pesquisa sobre a atividade de estudo. Conclui que o êxito na resolução de tarefas está determinado não somente por seu conteúdo objetivo, mas principalmente pelo motivo que impele a criança a agir, ou seja, pelo sentido que tem a atividade, o que expressa a dependência entre os processos intelectuais e os proces- 
sos motivacionais da atividade. Ademais, "o surgimento de novos motivos que originem novos sentidos também revela as possibilidade nascentes na esfera do intelecto" (Leontiev, 1983, p. 239).

Para que a aprendizagem seja consciente, o sujeito - no nosso caso, a criança - necessita saber por que precisa estudar: "É essencial que a criança compreenda que deve estudar para chegar a ser membro integral da sociedade, um construtor digno da mesma, um defensor de sua Pátria, etc., que o dever da criança é estudar" (p. 244). Obviamente, Leontiev apresenta esses motivos baseado na organização da sociedade socialista em que vivia. Um de nossos desafios seria pensar quais são os motivos sociais da atividade de estudo em nossa sociedade e quais deles guardam relação com os motivos humano-genéricos, universais.

De qualquer maneira, seja na sociedade socialista seja na capitalista, em um primeiro momento esses motivos têm caráter abstrato para a criança. Ela pode explicar racionalmente porque estuda e falar com convicção sobre esse tema, mas isso não significa que a atividade de estudo tenha um sentido pessoal coincidente com sua significação social. O que garante a conscientização daquilo que foi estudado é o sentido que têm as ações de estudo para o estudante, e para que a ação tenha sentido, seu fim deve ir ao encontro do motivo da atividade. Isto significa que a aprendizagem consciente se efetiva quando os conhecimentos são vivos para o sujeito, ocupam um lugar na sua vida real, têm um sentido vital, e não são somente respostas a condições externas, impostas por outras pessoas ou situações.

Quando a atividade de estudo não tem um sentido real, conectado aos motivos do próprio sujeito, a atividade torna-se formal, meramente reprodutiva. González Rey (2003), um dos autores contemporâneos que aprofundam a análise sobre a relação entre sentido e atividade de estudo, examina esse processo e estende essa análise às dificuldades de aprendizagem:

A não produção de sentido no processo de aprender conduz a um aprendizado formal, descritivo, rotineiro, memorístico, que não tem implicações ao sujeito que aprende. As dificuldades de aprendizado deixam, assim, de ser vistas só como resultado de problemas intelectuais ou orgânicos, e passam a ser consideradas expressão de processos subjetivos de natureza social (p.81).

Ao compreender a aprendizagem como processo de sentido, González Rey (2003) apresenta alguns aspectos teóricos referentesà educação escolar: propõe o desenvolvimento do aspecto subjetivo-dialógico da aprendizagem e enfatiza o lugar do sujeito que aprende e destaca o caráter criativo e produtivo do sujeito na atividade de aprendizagem e o papel do professor como arquiteto de processos dialógicos na sala de aula; portanto aposta nos processos de diálogo na reconfiguração dos sentidos da aprendizagem.

Embora concordemos com a importância do diálogo e dos aspectos levantados por González Rey, avaliamos que esses não são suficientes se descolados do papel da escola de proporcionar que os estudantes se apropriem das significações sociais na forma dos conteúdos escolares. Alertamos para possíveis interpretações (e suas implicações pedagógicas) advindas no ideário escolanovista e sua ênfase no aprender a aprender, como denunciou Duarte (2004), as quais tanto esvaziam do conhecimento as nossas escolas.

Nessa perspectiva, Góes e Cruz (2006), tendo como ponto de partida as formulações de Vigotski acerca da formação do pensamento conceitual, enfatizam o compromisso predominante da escola com o trabalho sobre o significado na aproximação do pensamento verdadeiramente conceitual, sistematizado e categorial; mas ressaltam que o conceito de sentido expande tal compromisso. $O$ sentido amplia o campo das significações à medida que participa na formação do pensamento de alta generalidade, articulando os âmbitos do vivencial e do categorial, que fundamentam, respectivamente, os conceitos cotidianos e os científicos.

O conceito de sentido é fundamental à educação escolar, visto que amplia a compreensão dos processos de aprendizagem e introduz elementos fundamentais para a compreensão do estudante não apenas como sujeito que aprende, mas também como sujeito que pensa, age, sente e escolhe a partir dos sentidos que atribui aos conhecimentos. Reconfigura-se, assim, o papel da imaginação e dos sentimentos no processo de aprendizagem:

As ideias de que a imaginação enriquece o conhecimento da realidade e favorece a atuação sobre ela, de que a elaboração conceitual e a ação criadora são atividades interdependentes e igualmente necessárias ao desenvolvimento do aluno e de que o instável e a diversidade da significação estão presentes na assimilação dos conhecimentos escolares devem vincular-se à projeção de uma escola desejável e de seus compromissos, pois avigoram critérios de referência - teóricos, políticos, metodológicos - para a busca de uma educação guiada pela indissolubilidade entre o conhecer e o transformar, de ações pedagógicas mais efetivas e de diretrizes promissoras para o ensinar-aprender (Góes, \& Cruz, 2006, p.42).

Destaca-se, nesta perspectiva, o papel da educação escolar na ampliação da imaginação e da criatividade, funções psicológicas superiores essenciais para a constituição da ciência, da arte e das demais produções humanas (Vigotski, 2006).Como síntese do texto, destaca-se uma ideia central: a ocorrência da aprendizagem depende do sentido que esta tenha para o sujeito, o que requer que o professor estruture a atividade de estudo de modo que os objetos a serem aprendidos tenham lugar estrutural na atividade dos estudantes.

\section{Referências}

Aguiar, W. M. J. (org.). (2006). Sentidos e Significados do Professor na Perspectiva Sócio-Histórica - Relatos de pesquisa. São Paulo: Casa do Psicólogo. 
Asbahr, F. S. F. (2005). Sentido pessoal e Projeto político pedagógico: análise da atividade pedagógica a partir da Psicologia HistóricoCultural. Dissertação de mestrado, Universidade de São Paulo, São Paulo-SP.

Barros, J. P. P., Paula, L.R.C., Pascual, J.G., Colaço, V.F.R., \& Ximenes, V.M. (2009). O conceito de "sentido" em Vygotsky: considerações epistemológicas e suas implicações para a investigação psicológica. Psicologia \& Sociedade, 21 (2), 174181.

Duarte, N. (2004) Formação do indivíduo, consciência e alienação: o ser humano na psicologia de A. N. Leontiev. Caderno CEDES, 24(62), 44-63.

Góes, M. C. R., \& Cruz, M.N. (2006). Sentido, significado e conceito: notas sobre as contribuições de Lev Vigotski. Pro-Posições (Unicamp), 17, 31-45.

González Rey, F. L. (2003). El aprendizajeenel enfoque históricocultural:sentido y aprendizaje. Em E. Arantes \& S.M. Chaves (Orgs). Concepções e práticas em formação de professores (pp. 57-69) Rio de Janeiro: DP\&A.

González Rey, F. L. (2007). As categorias sentido, sentido pessoal e sentido subjetivo: sua evolução e diferenciação na teoria históricocultural. Psicologia da Educação, 24, 155-179.

Leontiev, A. (1978). O desenvolvimento do psiquismo. Lisboa: Horizonte Universitário.
Leontiev, A. (1983). Actividad, conciencia e personalidad. Havana: Editorial Pueblo y Educacion.

Martins, L. M. (2004). A natureza histórico-social da personalidade. Caderno CEDES, 24(62), 82-99.

Marx, K. (1989). Manuscritos econômico-filosóficos. Em F. Fernandes (org). Marx e Engels: História (pp.146-181).São Paulo: Ed. Ática.

Namura, M. R. (2004). Por que Vygotsky se centra no sentido: uma breve incursão pela história do sentido na psicologia. Psicologia da Educação, 19, 91-117.

Silva, F. G. (2007). A dinâmica do psiquismo no processo de alienação, sofrimento e adoecimento ocupacional. Em Associação Brasileira de Educação e Marxismo (Org.), Anaisdo III Encontro Brasileiro de Educação e Marxismo. Feira de Santana-BA: UEFS.

Vigotski, L. S. (2000a). A construção do pensamento e da linguagem. São Paulo: Martins Fontes.

Vigotski, L. S. (2000b). Manuscrito de 1929 (Psicologia concreta do homem). Educação \& Sociedade, 21(71), 21-44.

Vigotsky, L.S. (2006). La imaginación y el arte en la infancia.Madrid: Ediciones Akal.

\section{Sobre a autora}

Flávia da Silva Ferreira Asbahr (flaviasfa@yahoo.com.br)

Professora do Departamento de Psicologia da Universidade Estadual Paulista (UNESP), Campus de Bauru. Doutora em Psicologia.

Fundação de Amparo à Pesquisa do Estado de São Paulo (FAPESP).

Trabalho anteriormente apresentado no V Encontro Brasileiro de Educação e Marxismo, realizado na Universidade Federal de Santa Catarina, Florianópolis, em 2011, e publicado nos Anais do evento.

As reflexões presentes no manuscrito são parte integrante da tese de doutorado da autora, intitulada "Por que aprender isso, professora?" Sentido pessoal e atividade de estudo na Psicologia Histórico-Cultural, defendida no Instituto de Psicologia da Universidade Estadual Paulista, em 2011, com orientação da Professora Dra. Marilene Proença Rebello de Souza. 